Discussion Paper No. 748

\title{
ZERO NOMINAL INTEREST RATES, UNEMPLOYMENT, EXCESS RESERVES AND DEFLATION IN A LIQUIDITY TRAP
}

\author{
Ryu-ichiro Murota \\ and \\ Yoshiyasu Ono
}

July 2009

The Institute of Social and Economic Research Osaka University

6-1 Mihogaoka, Ibaraki, Osaka 567-0047, Japan 


\title{
Zero Nominal Interest Rates, Unemployment, Excess Reserves and Deflation in a Liquidity Trap
}

\author{
Ryu-ichiro Murota* and Yoshiyasu Ono ${ }^{\dagger}$
}

\begin{abstract}
We present a dynamic and monetary model that consistently explains such various phenomena as unemployment, deflation, zero nominal interest rates and excess reserves held by commercial banks. These phenomena are commonly observed during the Great Depression in the United States, the recent long-run stagnation in Japan, and the worldwide financial crisis triggered by the US subprime loan problem of 2008. We show that an excessive liquidity preference leads to a liquidity trap and thereby generates the phenomena.
\end{abstract}

JEL Classification Codes: E12; E31; E41; E51

Keywords: Liquidity Trap; Zero Nominal Interest Rate; Persistent Unemployment; Excess Reserve; Deflation

*Address: Faculty of Economics, Kinki University, 3-4-1 Kowakae, Higashi-Osaka, Osaka 577-8502, Japan. E-mail: murota@eco.kindai.ac.jp.

$\dagger$ Address: Institute of Social and Economic Research, Osaka University, 6-1 Mihogaoka, Ibaraki, Osaka 567-0047, Japan. E-mail: ono@iser.osaka-u.ac.jp. Ono's research is financially supported by the Grants-in-Aid for Scientific Research, JSPS. 


\section{Introduction}

There are lots of common phenomena during the Great Depression in the United States and the recent long-run stagnation in Japan, both of which Krugman (1998) mentions as a liquidity trap. During the Great Depression, for example, the US unemployment rate rose from 3.2 percent in 1929 to a peak of 25.2 percent in 1933 and stayed higher than 10 percent for several years. Deflation occurred, nominal interest rates declined to nearly zero and excess reserves held by commercial banks expanded. ${ }^{1}$ Under the recent stagnation in Japan the unemployment rate rose from 2.1 percent in 1990 to a peak of 5.4 percent in 2002 and is still around 4.0 percent (see figure 1). Deflation has continued (figure 2), and nominal interest rates have been nearly zero (figure 3). ${ }^{2}$ And commercial banks held extensive excess reserves, which increased up to about six times as much as required by the Bank of Japan (figure 4).

These phenomena have again been observed in the United States since 2008. The seasonally adjusted unemployment rate has sharply increased from 4.9 percent in January 2008 to 7.2 percent in December 2008, and a monthly change in the consumer price index for all urban consumers has been negative or zero from August to December in 2008 (see the Bureau of Labor Statistics of the US Department of Labor). The federal funds rate has been decreased to nearly zero and excess reserves have massively expanded from 1.991 billion dollars in August 2008 to 767.412 billion dollars in December 2008 (see the

\footnotetext{
${ }^{1}$ See, e.g., Mankiw (2002, chapter 11, table 11-2) and Orphanides (2004, figures 1 and 2) for the transitions of price levels, unemployment rates and nominal interest rates. For the fall in nominal interest rates, see also Temin (1976, chapter 4, figures 4 and 5). Moreover, see Orphanides (2004, figure 3 (b)) and Wilcox (1984, table 1) for the increase in excess reserves.

${ }^{2}$ See, e.g., Fujiki, Okina and Shiratsuka (2001, figure 1) and Orphanides (2004, figure 4) for the movements of the policy interest rate and nominal rates of interest on government bonds.
} 
Board of Governors of the Federal Reserve System). ${ }^{3}$

Under such serious stagnation people tend to hold more cash and deposits than required for transactions -i.e., people have various motives of holding cash or deposits besides the transaction motive. Otani and Suzuki (2008) find that the volume of banknotes in circulation held by Japanese households for non-transaction motives increased from around 1 or 5 trillion yen in 1995 to around 30 trillion yen in 2007, that 70 percent of the total increase in banknotes in circulation from 1995 to 2007 was due to the increase in nontransaction demand, and that people held 120 trillion yen out of 310 trillion yen in demand deposits for such motives in 2007.

We analyze the phenomena that occurred during the stagnation periods in the US and Japan, using a model where both cash and interest-bearing deposits yield utility of liquidity à la Romer (1985) and Jones et al. (2004). We find that there are a certain value of the marginal utility of cash and a certain amount of full-employment output that divide the case of persistent unemployment from that of full employment. If the marginal utility of cash is less than the critical value, or equivalently if full-employment output is smaller than the critical amount, full employment obtains and nominal interest rates are positive in a steady state. If otherwise, nominal interest rates are zero and the marginal benefit of cash exceeds that of consumption, which makes people consume less than required to reach full employment and causes persistent unemployment and deflation to occur. Since it is indifferent

\footnotetext{
${ }^{3}$ The Federal Open Market Committee decided to control the federal funds rate in a range from zero to 0.25 percent in December 16, 2008.

${ }^{4}$ There are other approaches that consider liquidity of both cash and deposits. For example, Walsh (1984) extends a cash-in-advance model to a model where individuals must have cash and deposits in advance of buying goods. Simonsen and Cysne (2001) present a model in which both cash and deposits reduce transaction costs. However, these models are not suitable for treating money demand motivated by factors other than transactions.
} 
for commercial banks to hold reserves and interest-bearing assets under the zero nominal interest rates, they hold excess reserves, which lowers monetary aggregates and the money multiplier.

In the literature there are two well-known hypotheses about the cause of the Great Depression: the spending hypothesis (viz. the IS effect) and the money hypothesis (viz. the LM effect). ${ }^{5}$ Our paper emphasizes the monetary side of an economy and shows that excessive demand for cash yields persistent stagnation, as mentioned by the money hypothesis. However, the stagnation occurs - not because excessive demand for cash reduces monetary aggregates, raises interest rates and decreases investment - but because it absorbs purchasing power that would otherwise be directed toward consumption. Thus, our paper is more in conformity with the spending hypothesis than with the money hypothesis.

The stagnation mechanism of our model also differs from that of the liquidity trap model of Krugman (1998). By assuming rigid prices in the first period and perfect price adjustment that realizes full employment in the second period, he insists that deflation and zero nominal interest rates raise real interest rates and therefore reduce current consumption as a result of people's intertemporal decision making. ${ }^{6}$ Thus, stagnation is a short-run phenomenon in his setting. In our paper, in contrast, excessive demand for cash yields a shortage of consumption as a result of people's intratemporal preference between consumption and liquidity of cash and stagnation is a steady-state phenomenon.

The remainder of our paper is organized as follows. Sections 2 and 3

\footnotetext{
${ }^{5}$ See, e.g., Mankiw (2002, chapter 11) for a brief description on the two hypotheses.

${ }^{6}$ It seems that this mechanism is not consistent with Japan's recent slump. In fact, Baba et al. (2005, figure 4) show that Japan's real interest rates did not remarkably rise for the years 1991-2003 and slowly declined for the mid 1990s-2003.
} 
describe the structure and the dynamics of the model respectively. Whereas section 4 discusses the case where full employment is reached in a steady state, section 5 analyzes the case of persistent unemployment. In this case deflation occurs, nominal interest rates decline to zero, commercial banks hold excess reserves and the money multiplier approaches unity. Section 6 concludes. Stability analyses are set out in appendices.

\section{The Model}

The private sector consists of a representative firm, a representative commercial bank and a representative household. There are two assets, money and government bonds. Money is held by the household and the commercial bank whereas all government bonds are held by the commercial bank. ${ }^{7}$

\subsection{The Representative Firm and the Government}

We assume that the representative firm uses only labor to produce a commodity and that the labor productivity is constant, which we call $y$. Given real wage $w_{t}$ the firm chooses labor demand $l_{t}^{d}$ as follows:

$$
\begin{gathered}
l_{t}^{d}=0 \text { if } y<w_{t}\left(\equiv \frac{W_{t}}{P_{t}}\right), \\
0<l_{t}^{d}<\infty \text { if } y=w_{t}, \\
l_{t}^{d}=\infty \text { if } y>w_{t},
\end{gathered}
$$

where $W_{t}$ and $P_{t}$ are the nominal wage and the nominal commodity price respectively.

A monetary authority keeps nominal monetary base $M_{t}$ constant:

$$
M_{t}=M
$$

\footnotetext{
${ }^{7}$ In Japan most of government bonds are indeed held by Japanese financial institutions.
} 
A fiscal authority finances payments of interest on government bonds, $R_{t} B_{t}$, where $B_{t}$ and $R_{t}$ denote nominal government bonds and the nominal rate of interest on government bonds respectively, by issuing new government bonds $\dot{B}_{t}$ and collecting lump-sum tax $\tau_{t}$ :

$$
\dot{B}_{t}+P_{t} \tau_{t}=R_{t} B_{t}
$$

where the initial stock of nominal government bonds, $B_{0}$, is historically given. Let $\pi_{t}\left(\equiv \dot{P}_{t} / P_{t}\right), b_{t}\left(\equiv B_{t} / P_{t}\right)$ and $r_{t}\left(\equiv R_{t}-\pi_{t}\right)$ denote the inflation rate, real government bonds and the real rate of interest on government bonds respectively. Then the government's real budget equation is

$$
\dot{b}_{t}+\tau_{t}=r_{t} b_{t} .
$$

The fiscal authority follows a Ricardian rule:

$$
\tau_{t}=r_{t} b_{t}+\theta\left(b_{t}-\bar{b}\right), \quad \theta>0, \quad \bar{b}>0,
$$

where $\bar{b}$ is a target level of real government bonds. ${ }^{8}$ This rule yields the following simple dynamic equation of $b_{t}$ :

$$
\dot{b}_{t}=-\theta\left(b_{t}-\bar{b}\right),
$$

implying that $b_{t}$ converges to $\bar{b}$.

\subsection{The Representative Commercial Bank}

The representative commercial bank collects nominal deposits $D_{t}$ and holds government bonds $B_{t}$ so as to gain interest revenues $R_{t} B_{t}$. As assumed in Walsh (1984) and Romer (1985), the monetary authority requires the bank

\footnotetext{
${ }^{8}$ This rule is imposed basically for the validity of the no-Ponzi game condition of the government. See, e.g., Woodford (2001) and Schmitt-Grohé and Uribe (2007) for similar assumptions.
} 
to keep the reserve-deposit ratio higher than a fixed level, which we shall call $\epsilon$ :

$$
M_{t}^{B} \geq \epsilon D_{t}, \quad 0<\epsilon<1
$$

where $M_{t}^{B}$ denotes nominal reserve holdings. The bank maximizes its profit:

$$
R_{t} B_{t}-R_{t}^{D} D_{t}
$$

where $R_{t}^{D}$ is the nominal rate of interest on deposits, subject to reserve requirement (3) and the balance sheet:

$$
B_{t}+M_{t}^{B}=D_{t}
$$

The Lagrange function for the profit-maximization problem is given by

$$
\mathcal{L}_{t}=R_{t} B_{t}-R_{t}^{D} D_{t}+\kappa_{t}\left(M_{t}^{B}-\epsilon D_{t}\right)+\delta_{t}\left(D_{t}-B_{t}-M_{t}^{B}\right),
$$

where $\kappa_{t}$ and $\delta_{t}$ are the Lagrange multipliers associated with (3) and (4) respectively. The first-order conditions are

$$
\begin{gathered}
R_{t}=\delta_{t}, \\
\kappa_{t}=\delta_{t}, \\
R_{t}^{D}=\delta_{t}-\epsilon \kappa_{t}, \\
\kappa_{t} \geq 0, M_{t}^{B}-\epsilon D_{t} \geq 0, \kappa_{t}\left(M_{t}^{B}-\epsilon D_{t}\right)=0 .
\end{gathered}
$$

When $R_{t}>0$, the bank reduces reserves to the minimum level and consequently $(3)$ is binding $\left(\kappa_{t}>0\right)$. From (3)-(5), we therefore obtain

$$
R_{t}^{D}=(1-\epsilon) R_{t}>0, \quad D_{t}=\frac{B_{t}}{1-\epsilon}, \quad M_{t}^{B}=\frac{\epsilon}{1-\epsilon} B_{t} .
$$

When $R_{t}=0$, it is indifferent for the bank to hold reserves and interestbearing assets. Thus, (3) is not binding $\left(\kappa_{t}=0\right)$ and no equation of $(6)$ is valid. From (5) where $\kappa_{t}=0$, we find

$$
R_{t}=R_{t}^{D}=0
$$

We formally state this property: 
Lemma 1. $R_{t}=R_{t}^{D}=0$ if and only if (3) is not binding.

\subsection{The Representative Household}

Following Romer (1985) and Jones et al. (2004), we assume that the representative household's utility depends on consumption $c_{t}$, real cash holdings $m_{t}^{H}\left(\equiv M_{t}^{H} / P_{t}\right)$ where $M_{t}^{H}$ is the nominal value of $m_{t}^{H}$, and real deposit holdings $d_{t}\left(\equiv D_{t} / P_{t}\right)$. The household maximizes the following lifetime utility:

$$
\int_{0}^{\infty}\left[u\left(c_{t}\right)+V\left(m_{t}^{H}, d_{t}\right)\right] \exp (-\rho t) \mathrm{d} t,
$$

where $\rho(>0)$ is the subjective discount rate, $u\left(c_{t}\right)$ is the utility of consumption and $V\left(m_{t}^{H}, d_{t}\right)$ is the utility of liquidity. They satisfy normal properties:

$$
\begin{gathered}
u^{\prime}(\cdot)>0, \quad u^{\prime \prime}(\cdot)<0, \quad u^{\prime}(0)=\infty, \quad u^{\prime}(\infty)=0 ; \\
\left(\frac{\partial V}{\partial m_{t}^{H}} \equiv\right) V_{m}(\cdot, \cdot)>0, \quad\left(\frac{\partial^{2} V}{\partial m_{t}^{H^{2}}} \equiv\right) V_{m m}(\cdot, \cdot)<0, \\
V_{m}\left(0, d_{t}\right)=\infty, \quad V_{m}\left(\infty, d_{t}\right)=0 \\
\left(\frac{\partial V}{\partial d_{t}} \equiv\right) V_{d}(\cdot, \cdot)>0, \quad\left(\frac{\partial^{2} V}{\partial d_{t}^{2}} \equiv\right) V_{d d}(\cdot, \cdot)<0, \\
V_{d}\left(m_{t}^{H}, 0\right)=\infty, \quad V_{d}\left(m_{t}^{H}, \infty\right)=0 .
\end{gathered}
$$

$V\left(m_{t}^{H}, d_{t}\right)$ is further assumed to be linear homogeneous and hence marginal utility of cash $V_{m}\left(m_{t}^{H}, d_{t}\right)$ and that of deposits $V_{d}\left(m_{t}^{H}, d_{t}\right)$ depend on $m_{t}^{H} / d_{t}:{ }^{9}$

$$
V_{m}\left(m_{t}^{H}, d_{t}\right) \equiv v_{m}\left(x_{t}\right), \quad V_{d}\left(m_{t}^{H}, d_{t}\right) \equiv v_{d}\left(x_{t}\right),
$$

where $x_{t}$ is the cash-deposit ratio defined such that

$$
x_{t} \equiv \frac{m_{t}^{H}}{d_{t}} .
$$

\footnotetext{
${ }^{9}$ Similarly, Jones et al. (2004) assume a constant elasticity of substitution function of cash and deposits.
} 
The properties given in (7) imply $v_{m}\left(x_{t}\right)$ and $v_{d}\left(x_{t}\right)$ to satisfy

$$
\begin{aligned}
& v_{m}^{\prime}\left(x_{t}\right)<0, \quad v_{m}(0)=\infty, \quad v_{m}(\infty)=0 \\
& v_{d}^{\prime}\left(x_{t}\right)>0, \quad v_{d}(0)=0, \quad v_{d}(\infty)=\infty
\end{aligned}
$$

The household's assets $a_{t}$ consist of cash $m_{t}^{H}$ and deposits $d_{t}$ :

$$
a_{t}=m_{t}^{H}+d_{t}
$$

Note that there is no equity since the firm value is zero under the linear technology. The flow budget equation is

$$
\dot{a}_{t}=r_{t}^{D} d_{t}-\pi_{t} m_{t}^{H}+w_{t} l_{t}-c_{t}-\tau_{t}
$$

where $r_{t}^{D}$ is the real rate of interest on deposits:

$$
r_{t}^{D} \equiv R_{t}^{D}-\pi_{t}
$$

and $l_{t}$ is the realized amount of labor supply. The household's labor supply is inelastic and normalized to unity, but it may not be fully employed. Therefore, realized labor supply $l_{t}$ is determined by the short side of labor demand and supply:

$$
l_{t}=\min \left\{l_{t}^{d}, 1\right\} .
$$

The first-order conditions for the utility-maximization problem subject to $(10)$ and (11) are

$$
\begin{gathered}
u^{\prime}\left(c_{t}\right)=\lambda_{t}, \\
-\pi_{t} \lambda_{t}+v_{m}\left(x_{t}\right)=\gamma_{t}, \\
r_{t}^{D} \lambda_{t}+v_{d}\left(x_{t}\right)=\gamma_{t}, \\
\dot{\lambda}_{t}-\rho \lambda_{t}=-\gamma_{t},
\end{gathered}
$$


where $\lambda_{t}$ is the co-state variable associated with (11) and $\gamma_{t}$ is the Lagrange multiplier associated with (10). The transversality condition is

$$
\lim _{t \rightarrow \infty} \lambda_{t} a_{t} \exp (-\rho t)=0
$$

From (12) and (14) we obtain

$$
\rho+\eta\left(c_{t}\right) \frac{\dot{c}_{t}}{c_{t}}+\pi_{t}=\frac{v_{m}\left(x_{t}\right)}{u^{\prime}\left(c_{t}\right)}=R_{t}^{D}+\frac{v_{d}\left(x_{t}\right)}{u^{\prime}\left(c_{t}\right)},
$$

where $\eta\left(c_{t}\right) \equiv-u^{\prime \prime}\left(c_{t}\right) c_{t} / u^{\prime}\left(c_{t}\right)$. The left-hand side of (16) is the intertemporal marginal rate of substitution of consumption measured in nominal terms, the middle is the marginal benefit of cash given by the intratemporal marginal rate of substitution between cash and consumption, and the right-hand side is the marginal benefit of deposits given by the sum of the nominal rate of interest on deposits and the intratemporal marginal rate of substitution between deposits and consumption.

\section{The Dynamics}

We obtain the dynamics of the present economy from all agents' behavior presented in the previous section. The money market equilibrium condition is

$$
M_{t}^{H}+M_{t}^{B}=M
$$

Adjustment of nominal wage $W_{t}$ is assumed to be sluggish:

$$
\frac{\dot{W}_{t}}{W_{t}}=\alpha\left(l_{t}^{d}-1\right),
$$

where $\alpha(>0)$ is exogenous and constant and $W_{0}$ is historically given. ${ }^{10} \mathrm{In}$ contrast, commodity price $P_{t}$ perfectly adjusts. Thus, the second equation

\footnotetext{
${ }^{10}$ Many economists have long explored how nominal or real wages adjust. Although this issue is still interesting and important, we assume a simple adjustment process because
} 
of (1) is valid at any point in time:

$$
\frac{W_{t}}{P_{t}}=y \text { for } \forall t
$$

and the commodity market is always in equilibrium

$$
c_{t}=y l_{t}
$$

where from (13)

$$
l_{t}=l_{t}^{d} \leq 1
$$

Note that $y$ can be taken as full-employment output since the representative household's labor endowment is unity.

From (18)-(21) we find $\pi_{t}$ to be

$$
\pi_{t}=\alpha\left(\frac{c_{t}}{y}-1\right) .
$$

Since $M_{t}$ is constant at $M$, the dynamic equation of real money balances $m_{t}\left(\equiv M / P_{t}\right)$ is

$$
\frac{\dot{m}_{t}}{m_{t}}=-\pi_{t}=-\alpha\left(\frac{c_{t}}{y}-1\right)
$$

From the second and third equations of (6), (8), the second equality of (16), and (17), cash-deposit ratio $x_{t}$ is

$$
\begin{aligned}
& x_{t}=(1-\epsilon) \frac{m_{t}}{b_{t}}-\epsilon \equiv x\left(m_{t}, b_{t}\right) \text { if } R_{t}^{D}>0, \\
& x_{t}=\tilde{x} \text { if } R_{t}^{D}=0
\end{aligned}
$$

our purpose is not to analyze why wages are rigid but to show why unemployment persists even though wages continue to adjust, as was the case under the Great Depression of the 1930s and Japan's recent slump. If wages instantaneously adjust so that demand always matches supply in the labor market, the possibility of unemployment is intrinsically avoided. However, it can be shown that there is no equilibrium path under such perfect wage adjustment if a liquidity preference for cash is excessive and/or if full-employment output is large (see section 5). Moreover, it is known that the original Phillips curve holds well in Japan (see, e.g., Smith, 2008). 
where $\tilde{x}$ satisfies

$$
v_{m}(\tilde{x})=v_{d}(\tilde{x})
$$

Note that $\tilde{x}$ is uniquely determined under the properties in (9). From (24) and (25), we find that in contrast to the standard money-in-the-utility-function model the marginal utility of cash is positive even when nominal interest rates $R_{t}^{D}$ and $R_{t}$ are zero. It is because from (16) both cash and deposits yield utility of liquidity and $R_{t}^{D}$ merely fills the gap between the liquidity premiums of the two.

The first equality of (16), (22) and (24) give the dynamic equation of $c_{t}$ :

$$
\begin{aligned}
& \frac{\dot{c}_{t}}{c_{t}}=\sigma\left(c_{t}\right)\left[-\alpha\left(\frac{c_{t}}{y}-1\right)+\frac{v_{m}\left(x\left(m_{t}, b_{t}\right)\right)}{u^{\prime}\left(c_{t}\right)}-\rho\right] \text { if } R_{t}^{D}>0, \\
& \frac{\dot{c}_{t}}{c_{t}}=\sigma\left(c_{t}\right)\left[-\alpha\left(\frac{c_{t}}{y}-1\right)+\frac{v_{m}(\tilde{x})}{u^{\prime}\left(c_{t}\right)}-\rho\right] \text { if } R_{t}^{D}=0,
\end{aligned}
$$

where $\sigma\left(c_{t}\right) \equiv 1 / \eta\left(c_{t}\right)$. (2), (23) and (26) characterize the dynamic behavior of the present economy.

\section{The Full Employment Steady State}

This section shows that full employment obtains and nominal interest rates $R$ and $R^{D}$ are positive in a steady state if

$$
\rho>\frac{v_{m}(\tilde{x})}{u^{\prime}(y)} .
$$

In the full employment steady state, from (20), (23) and the first equation of $(26)$,

$$
c=y, \quad l=1, \quad \pi=0, \quad \rho=\frac{v_{m}\left(x^{*}\right)}{u^{\prime}(y)},
$$

where $x^{*}$ denotes the cash-deposit ratio in this state and is uniquely determined owing to the properties of $v_{m}(\cdot)$ in $(9)$. 
Since $v_{m}^{\prime}(x)<0$ and $v_{d}^{\prime}(x)>0$ as shown by (9), equations (25) and (27) and the last equation of (28) yield

$$
x^{*}<\tilde{x}, \quad \rho=\frac{v_{m}\left(x^{*}\right)}{u^{\prime}(y)}>\frac{v_{m}(\tilde{x})}{u^{\prime}(y)}=\frac{v_{d}(\tilde{x})}{u^{\prime}(y)}>\frac{v_{d}\left(x^{*}\right)}{u^{\prime}(y)} .
$$

Therefore, from (6) and (16), the nominal interest rates are positive:

$$
R^{D}=(1-\epsilon) R=\frac{v_{m}\left(x^{*}\right)}{u^{\prime}(y)}-\frac{v_{d}\left(x^{*}\right)}{u^{\prime}(y)}>0 .
$$

Since the cash-deposit ratio is given by the last equation of (28) and lemma

1 implies that reserve requirement (3) is binding in this state, (2), (6), (8) and (17) yield

$$
b=\bar{b}, \quad d=\frac{\bar{b}}{1-\epsilon}, \quad m^{H}=\frac{x^{*} \bar{b}}{1-\epsilon}, \quad m^{B}=\frac{\epsilon \bar{b}}{1-\epsilon}, \quad m=\frac{\left(x^{*}+\epsilon\right) \bar{b}}{1-\epsilon} .
$$

Using $d, m^{H}$ and $m$ given in (30) we find the money multiplier to be larger than unity:

$$
\frac{M^{H}+D}{M}\left(=\frac{m^{H}+d}{m}\right)=\frac{x^{*}+1}{x^{*}+\epsilon}>1 .
$$

Moreover, as shown in appendix A, there is a unique path converging to the full employment steady state. Thus we obtain the following proposition:

Proposition 1. The economy converges to the full employment steady state represented by (28)-(30) if (27) holds.

\section{The Unemployment Steady State}

In the previous section we find that under (27) full employment is eventually reached, in other words, unemployment is a short-run phenomenon. However, unemployment often lasts long, as did under the Great Depression in the 1930s and Japan's lost decade. This section shows that if (27) is invalid, i.e.,

$$
\rho<\frac{v_{m}(\tilde{x})}{u^{\prime}(y)}
$$


persistent unemployment occurs, the nominal interest rates are zero, deflation lasts, excess reserves are held by the commercial bank and the money multiplier equals unity in a steady state. ${ }^{11}$ (31) implies that the marginal benefit of cash (the right-hand side) exceeds that of consumption (the lefthand side) if consumption is large enough to realize full employment. It is valid if either labor productivity $y$ (which equals full-employment output) or marginal utility of cash $v_{m}$ is large enough.

From (9) and (31), $\tilde{x}$ in (25) and $x^{*}$ in (28) satisfy

$$
x^{*}>\tilde{x}, \quad \rho=\frac{v_{m}\left(x^{*}\right)}{u^{\prime}(y)}<\frac{v_{m}(\tilde{x})}{u^{\prime}(y)}=\frac{v_{d}(\tilde{x})}{u^{\prime}(y)}<\frac{v_{d}\left(x^{*}\right)}{u^{\prime}(y)},
$$

which implies that if $x$ is determined so that it equates the marginal benefit of cash to that of consumption under full employment then the nominal rate of interest on deposits must be negative:

$$
R^{D}=\frac{v_{m}\left(x^{*}\right)}{u^{\prime}(y)}-\frac{v_{d}\left(x^{*}\right)}{u^{\prime}(y)}<0 .
$$

If $R^{D}<0$, however, the commercial bank can unlimitedly increase its profit by collecting deposits and holding reserves, which increases the bank's demand for deposits to infinity. $R^{D}$ therefore rises up to zero, and consequently

$$
R^{D}=0, \quad R=0 \text {. }
$$

In this state excess reserves are held by the commercial bank, as stated by lemma 1, and the cash-deposit ratio is

$$
x=\tilde{x},
$$

\footnotetext{
${ }^{11}$ We ignore the infinitesimal possibility that neither (27) nor (31) is valid, that is,$$
\rho=\frac{v_{m}(\tilde{x})}{u^{\prime}(y)} .
$$

In the steady state of this case, the zero nominal interest rates and full employment go together.
} 
as shown by (24).

From (31) and (33), the last equation of (28) is obviously invalid and hence the full employment steady state is unreachable. From the second equation of (26) we obtain

$$
\rho+\alpha\left(\frac{c}{y}-1\right)=\frac{v_{m}(\tilde{x})}{u^{\prime}(c)},
$$

instead of the last equation of (28). Under (31) the left-hand side of (34) is smaller than the right-hand side if $c=y$. Thus, in order for $c$ that satisfies (34) to exist uniquely within $(0, y)$ the left-hand side of (34) must be larger than the right-hand side if $c=0$, i.e.,

$$
\rho>\alpha .
$$

From (31) and (35), the slope of the right-hand side of (34) must be steeper than that of the left-hand side at the value of $c$ satisfying (34):

$$
\frac{\alpha}{y}<-\frac{v_{m}(\tilde{x}) u^{\prime \prime}(c)}{\left[u^{\prime}(c)\right]^{2}} .
$$

As shown in appendix B, (36) assures the saddle-path stability in the neighborhood of the present steady state and hence there is a unique path to reach the steady state.

Let us summarize the present mechanism of persistent unemployment. Since $R^{D}$ cannot be negative, it is stuck at zero, which makes $x$ equal $\tilde{x}$ and $v_{m}(x)$ equal $v_{m}(\tilde{x})$. Since the marginal benefit of cash exceeds that of consumption (viz. the time preference rate) under full employment, as shown by (31), the household reduces consumption to less than full-employment output $y$ in order to hold more cash. Hence persistent unemployment arises (from (20) and (21) $l=l^{d}<1$ under $c<y$ ). ${ }^{12}$

\footnotetext{
${ }^{12}$ Ono $(1994,2001)$ finds that an aggregate demand shortage and unemployment occur
} 
From (23) where $c<y$, deflation arises and real money balances continue to increase:

$$
\frac{\dot{m}}{m}=-\pi>0
$$

Using (2), (4), (8), (17), (33) and (37) we find

$$
b=\bar{b}, \quad d=\frac{m+\bar{b}}{1+\tilde{x}}=\infty, \quad m^{H}=\frac{\tilde{x}(m+\bar{b})}{1+\tilde{x}}=\infty, \quad m^{B}=\frac{m-\tilde{x} \bar{b}}{1+\tilde{x}}=\infty .
$$

From (34) and (38), deflation continues to expand real cash and deposit holdings but does not stimulate consumption -i.e., the Pigou effect does not work. $^{13}$

From (17) and the second and fourth properties of (38) we obtain

$$
\frac{M^{B}}{D}=\lim _{m \rightarrow \infty} \frac{1-\tilde{x} \bar{b} / m}{1+\bar{b} / m}=1, \quad M^{H}+D=M^{H}+M^{B}=M,
$$

which shows that the money multiplier approaches unity and monetary aggregates $M^{H}+D$ decline to monetary base $M$.

Since (4), (10) and (17) yield

$$
a\left(=m^{H}+d\right)=m+b,
$$

from (37) and (38) we find

$$
\frac{\dot{a}}{a}=\frac{\dot{m} / m}{1+b / m}+\frac{\dot{b} / b}{m / b+1}=\frac{\dot{m}}{m}=-\pi .
$$

as a steady-state phenomenon if there is a positive lower bound for the marginal utility of money. See also Matsuzaki (2003), Hashimoto (2004), Johdo (2006, 2008a, 2008b), Ono (2006), Rodriguez-Arana (2007) and Johdo and Hashimoto (2009) for the same type of unemployment. Whereas they assume the marginal utility of money to remain positive, we do not assume it and nevertheless persistent unemployment occurs. In our paper the nonnegativity of nominal interest rates causes the marginal utility of money to stay positive.

${ }^{13}$ Ono $(1994,2001)$ also finds that the Pigou effect does not work under insatiable liquidity preference. 
Time differentiation of the first equation of (14), the first equality of (16) and the above property lead to

$$
\lim _{t \rightarrow \infty} \frac{\dot{\lambda}_{t}}{\lambda_{t}}+\frac{\dot{a}_{t}}{a_{t}}-\rho=\lim _{t \rightarrow \infty}-\eta\left(c_{t}\right) \frac{\dot{c}_{t}}{c_{t}}-\pi-\rho=-\frac{v_{m}(\tilde{x})}{u^{\prime}(c)}<0,
$$

implying that transversality condition (15) is satisfied although $m$ permanently expands. ${ }^{14}$

We summarize the above discussion in the following proposition:

Proposition 2. The economy reaches the unemployment steady state characterized by (32)-(34), (37) and (38) if (31) and (35) are valid.

As observed during the Great Depression in the US and the recent stagnation in Japan, unemployment persists, leading to deflation, and nominal interest rates $R^{D}$ and $R$ are zero, causing the commercial bank to hold excess reserves. Moreover, the latter is supported by some empirical papers. For example, Wilcox (1984) attributes 80 percent of the increase in excess reserves during the Great Depression to a significant fall in interest rates. Ogawa (2007) reports a similar result in Japan of the late 1990s.

The result shown by (39) is also consistent with both stagnation periods. For instance, Wheelock (1992, figure 10) illustrates a significant fall in the money multiplier during the Great Depression, and figure 5 exhibits a similar phenomenon that occurred during Japan's recent stagnation. In the present steady state the contraction in monetary aggregates is not the cause but the result of slump. This causality is opposite to the money hypothesis à la Friedman and Schwartz (1963) but the same as Temin (1976) and Krugman (1998).

\footnotetext{
${ }^{14}$ Even if $b$ does not follow (2) but continues to increase, the transversality condition holds and the money multiplier remains unity as long as the expansion rate of $b$ is less than that of $m$.
} 
Note that (32)-(34), (37) and (38) are valid regardless of the amount of $M$. Thus, even if the monetary authority supplies a larger amount of $M$, all of the real variables remain unaffected and only nominal cash and excess reserve holdings increase. It is indeed the case during Japan's recent long-run stagnation. The Bank of Japan expanded the monetary base from 65.7961 trillion yen in March 2001 to 108.7749 trillion yen in March 2006 but most of the increased money were absorbed as excess reserves (see figure 4) while neither aggregate demand nor employment was significantly stimulated.

\section{Concluding Remarks}

We present a simple model where a representative household derives utility from liquidity of both cash and deposits, a representative commercial bank is required to hold money as reserves, and nominal wages sluggishly adjust. In this setting we find that there are a certain value of the marginal utility of cash and a certain amount of full-employment output that divide the case of persistent unemployment from that of full employment.

If the marginal utility of cash is less than the critical value, or equivalently, if full-employment output is smaller than the critical amount, full employment obtains and nominal interest rates are positive in a steady state. If otherwise, typical phenomena of persistent stagnation that are allegedly due to a liquidity trap obtain in a steady state. Nominal interest rates are stuck at zero and the commercial bank holds excess reserves. The marginal benefit of cash would be larger than that of consumption if the household consumed enough to realize full employment. Therefore, the household reduces consumption so as to increase cash holdings, which creates an aggregate demand shortage, unemployment and deflation. These phenomena were common during the Great Depression in the US and the recent long-run 
stagnation in Japan.

The present mechanism of stagnation is more in conformity with the spending hypothesis than with the money hypothesis although the monetary side plays a crucial role in generating stagnation. The stagnation occurs - not because excessive demand for cash decreases monetary aggregates, keeps an interest rate too high and prevents investment from increasing - but because it absorbs purchasing power that would otherwise be directed toward consumption and generates a shortage of aggregate demand. Furthermore, this mechanism is different from such recent studies of liquidity traps as Krugman (1998) who shows that a combination of deflation and zero nominal interest rates increases real interest rates and decreases current consumption. 


\section{Appendix A The Stability of the Full Employ- ment Steady State}

In the neighborhood of the steady state where $b, m$ and $c$ are given by (28) and (30), linearizing (2), (23) and the first equation of (26) yields the characteristic equation:

$$
\left|\begin{array}{ccc}
-\theta-z & 0 & 0 \\
0 & -z & -\frac{\alpha m}{y} \\
\frac{\sigma c v_{m}^{\prime} x_{b}}{u^{\prime}} & \frac{\sigma c v_{m}^{\prime} x_{m}}{u^{\prime}} & \sigma c\left(-\frac{\alpha}{y}-\frac{v_{m}}{u^{\prime 2}} u^{\prime \prime}\right)-z
\end{array}\right|=0
$$

where $z$ is a characteristic root and $x_{b}$ and $x_{m}$ are partial derivatives of the first equation of $(24)$ :

$$
x_{b}=-(1-\epsilon) \frac{m}{b^{2}}<0, \quad x_{m}=\frac{1-\epsilon}{b}>0 .
$$

One of the three characteristic roots is

$$
z=-\theta<0
$$

and the other two satisfy

$$
z^{2}+\sigma c\left(\frac{\alpha}{y}+\frac{v_{m}}{u^{\prime 2}} u^{\prime \prime}\right) z+\frac{\alpha m \sigma c v_{m}^{\prime} x_{m}}{y u^{\prime}}=0
$$

where the constant term is negative. Thus, the characteristic equation has one positive and two negative roots.

From (19), $P_{0}$ is determined so that $W_{0} / P_{0}=y$, where $W_{0}$ is historically given. Then, $m_{0}$ and $b_{0}$ are given as $m_{0}=y M / W_{0}$ and $b_{0}=y B_{0} / W_{0}$, where

$y$ and $M$ are exogenous and constant and $B_{0}$ is historically given. Since $c_{0}$ is jumpable and $m_{0}$ and $b_{0}$ are not, there is a unique path converging to the full employment steady state mentioned in proposition 1. 


\section{Appendix B The Stability of the Unemploy- ment Steady State}

By replacing $m_{t}$ by $q_{t}\left(\equiv 1 / m_{t}\right)$ and linearizing $(2),(23)$ and the second equation of (26) in the neighborhood of the steady state where $q=0, b=\bar{b}$ and $c$ satisfies (34), we obtain the following characteristic equation:

$$
\left|\begin{array}{ccc}
-\theta-z & 0 & 0 \\
0 & \alpha\left(\frac{c}{y}-1\right)-z & 0 \\
0 & 0 & \sigma c\left(-\frac{\alpha}{y}-\frac{v_{m}}{u^{\prime 2}} u^{\prime \prime}\right)-z
\end{array}\right|=0 .
$$

The roots of this equation are

$$
z=-\theta<0, \quad z=\alpha\left(\frac{c}{y}-1\right)<0, \quad z=\sigma c\left(-\frac{\alpha}{y}-\frac{v_{m}}{u^{\prime 2}} u^{\prime \prime}\right)>0
$$

where the last inequality holds under (36). Note that (36) must hold under (31) and (35). Since $c_{0}$ is jumpable but neither $q_{0}\left(=1 / m_{0}\right)$ nor $b_{0}$ is, there is a unique path to reach the unemployment steady state described in proposition 2 . 


\section{References}

[1] Baba, N, S. Nishioka, N. Oda, M. Shirakawa, K. Ueda, and H. Ugai (2005), “Japan's Deflation, Problems in the Financial System, and Monetary Policy," Monetary and Economic Studies, Vol. 23, pp. 47-111.

[2] Friedman, M. and A. J. Schwartz (1963), A Monetary History of the United States, Princeton: Princeton University Press.

[3] Fujiki, H., K. Okina, and S. Shiratsuka (2001), "Monetary Policy under Zero Interest Rate: Viewpoints of Central Bank Economists," Monetary and Economic Studies, Vol. 19, pp. 89-130.

[4] Hashimoto, K. (2004), "Intergenerational Transfer and Effective Demand," Economics Bulletin, Vol. 5, pp. 1-13.

[5] Johdo, W. (2006), "Geographical Space and Effective Demand under Stagnation," Australian Economic Papers, Vol. 45, pp. 286-298.

[6] Johdo, W. (2008a), "Is Openness Good for Stagnation?," Journal of Economic Integration, Vol. 23, pp. 24-41.

[7] Johdo, W. (2008b), "Production Subsidy as a Macroeconomic Policy in a Stagnation Economy," Singapore Economic Review, Vol. 53, pp. 317-333.

[8] Johdo, W. and K. Hashimoto (2009), "International Relocation, the Real Exchange Rate and Effective Demand," Japan and the World Economy, Vol. 21, pp. 39-54. 
[9] Jones, B., G. Asaftei, and L. Wang (2004), "Welfare Cost of Inflation in a General Equilibrium Model with cash and Interest-Bearing Deposits," Macroeconomic Dynamics, Vol. 8, pp. 493-517.

[10] Krugman, P. R. (1998), "It's Baaack: Japan's Slump and the Return of the Liquidity Trap," Brookings Papers on Economic Activity, pp. 13787.

[11] Mankiw, N. G. (2002), Macroeconomics Fifth Edition, New York: Worth Publishers.

[12] Matsuzaki, D. (2003), "The Effects of a Consumption Tax on Effective Demand under Stagnation," Japanese Economic Review, Vol. 54, pp. $101-118$.

[13] Ogawa, K. (2007), "Why Commercial Banks Held Excess Reserves: The Japanese Experience of the Late '90s," Journal of Money, Credit, and Banking, Vol. 39, pp. 241-257.

[14] Ono, Y. (1994), Money, Interest and Stagnation, New York: Oxford University Press.

[15] Ono, Y. (2001), "A Reinterpretation of Chapter 17 of Keynes's General Theory: Effective Demand Shortage under Dynamic Optimization," International Economic Review, Vol. 42, pp. 207-236.

[16] Ono, Y. (2006), "International Asymmetry in Business Activity and Appreciation of a Stagnant Country's Currency," Japanese Economic Review, Vol. 57, pp. 101-120. 
[17] Orphanides, A. (2004), "Monetary Policy in Deflation: the Liquidity Trap in History and Practice," North American Journal of Economics and Finance, Vol. 15, pp. 101-124.

[18] Otani, A. and T. Suzuki (2008), "Background to the High Level of Banknotes in Circulation and Demand Deposits," Bank of Japan Review, No. 2008-E-5.

[19] Rodriguez-Arana, A. (2007), "Inflation and the Public Deficit When the Utility of Money is Insatiable," Japanese Economic Review, Vol. 58, pp. 238-254.

[20] Romer, D. (1985), "Financial Intermediation, Reserve Requirements, and Inside Money," Journal of Monetary Economics, Vol. 16, pp. 175194.

[21] Schmitt-Grohé, S. and M. Uribe (2007), "Optimal Simple and Implementable Monetary and Fiscal Rules," Journal of Monetary Economics, Vol. 54, pp. 1702-1725.

[22] Simonsen, M. H. and R. P. Cysne (2001), "Welfare Costs of Inflation and Interest-bearing Money," Journal of Money, Credit, and Banking, Vol. 33, pp. 90-100.

[23] Smith, G. W. (2008), "Japan's Phillips Curve Looks Like Japan," Journal of Money, Credit, and Banking, Vol. 40, pp. 1325-1326.

[24] Temin, P. (1976), Monetary Forces Cause the Great Depression?, New York: Norton.

[25] Walsh, C. E. (1984), "Optimal Taxation by the Monetary Authority," NBER Working Paper, No. 1375. 
[26] Wheelock, D. C. (1992), "Monetary Policy in the Great Depression: What the Fed did, and Why," Federal Reserve Bank of St. Louis Review, Vol. 74 , pp. 3-28.

[27] Wilcox, J. A. (1984), "Excess Reserves in the Great Depression," NBER Working Paper, No. 1374.

[28] Woodford, M. (2001), "Fiscal Requirements for Price Stability," Journal of Money, Credit, and Banking, Vol. 33, pp. 669-728. 


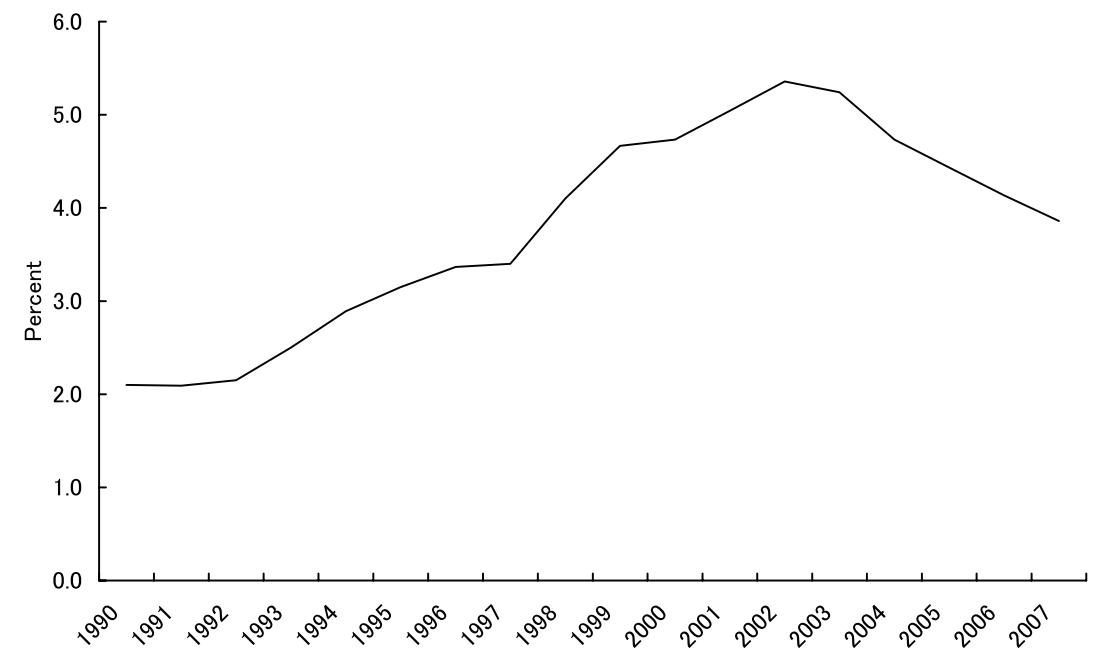

Source: The Statistics Bureau, Ministry of Internal Affairs and Communications, Japan.

Figure 1: The average rate of unemployment in Japan for the years 19902007. 


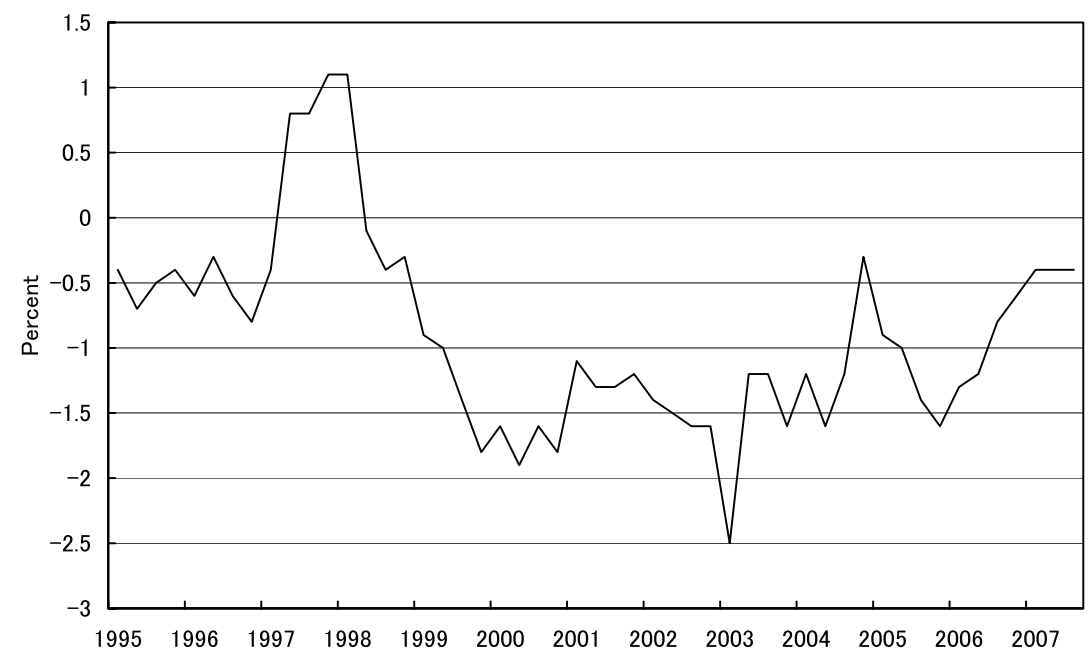

Source: The Cabinet Office, Government of Japan.

Figure 2: The year-to-year percentage change in the GDP deflator in Japan from January-March 1995 to July-September 2007. 


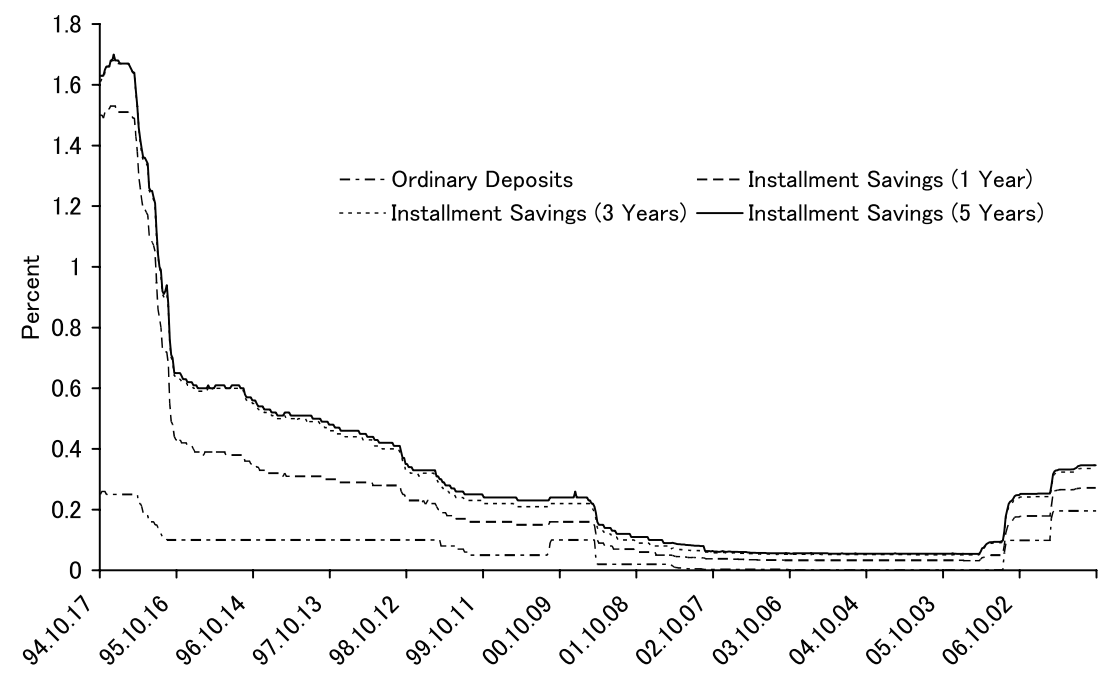

Sources: The Bank of Japan.

Note: Ordinary deposits and installment savings correspond to demand and time deposits respectively.

Figure 3: The nominal rates of interest on deposits from October 17, 1994 to September 24, 2007. 


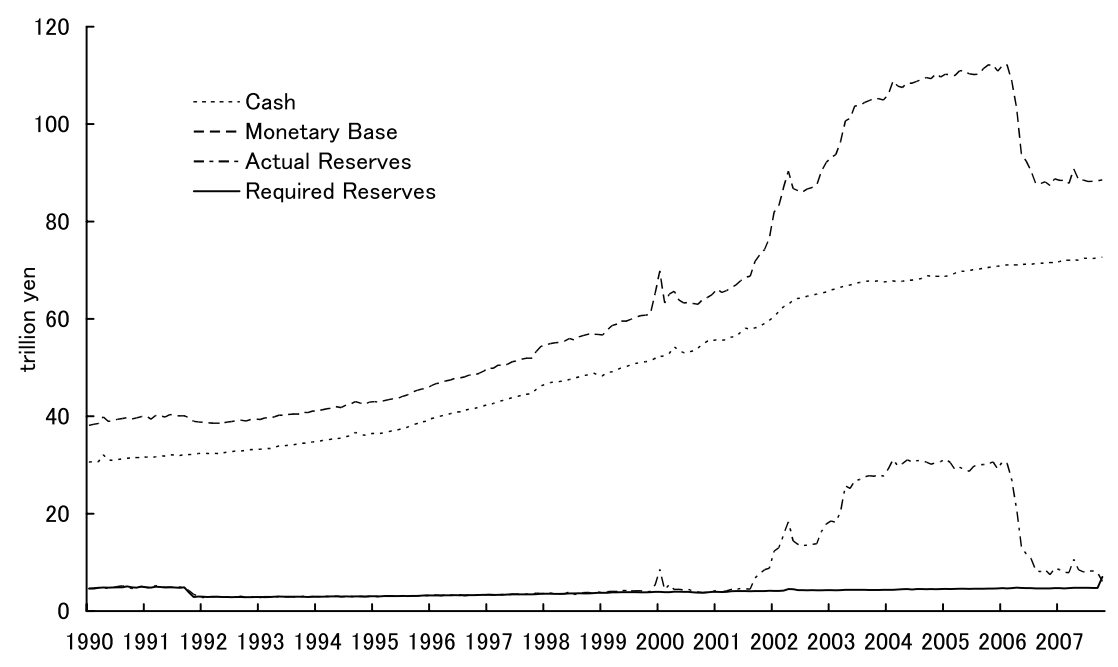

Sources: The Bank of Japan.

Figure 4: The monetary base, cash, and actual and required reserves in Japan from January 1990 to October 2007. 


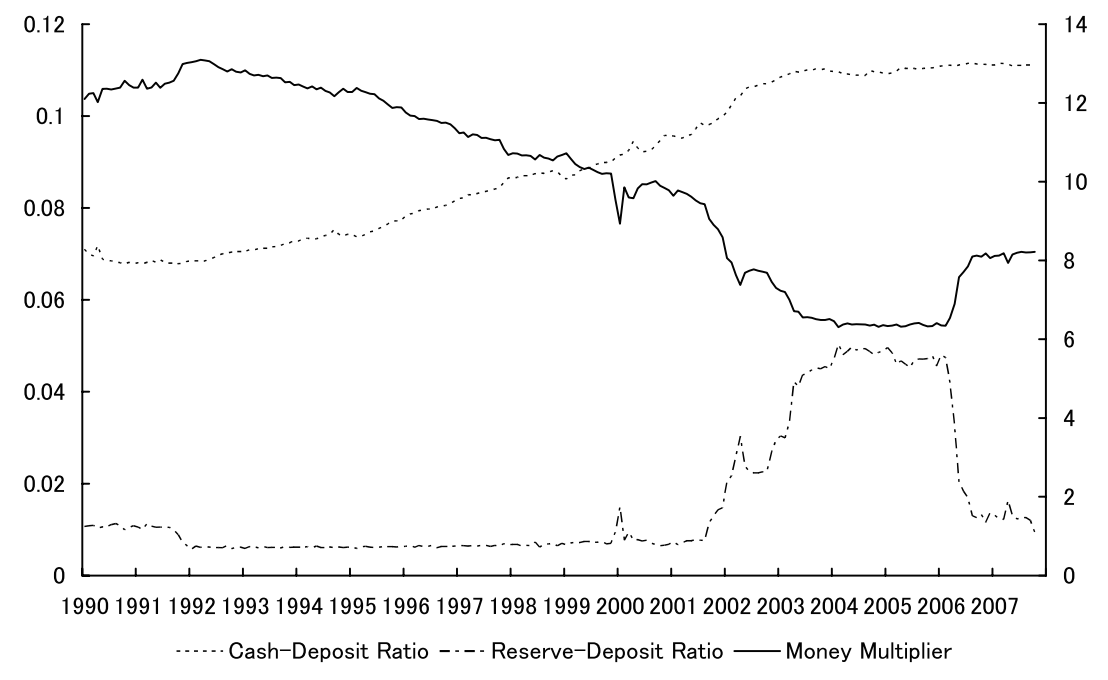

Sources: The Bank of Japan.

Note: The left and right axes measure the ratios and the money multiplier respectively.

Figure 5: The money multiplier, the cash-deposit ratio and the reservedeposit ratio in Japan from January 1990 to October 2007. 